\title{
Effects of the ginkgo biloba extract on the superoxide dismutase activity and apoptosis of endothelial progenitor cells from diabetic peripheral blood
}

\author{
M. Zhao' ${ }^{1}$ X.-X. Wang ${ }^{1}$ and W.-H. Wan ${ }^{2}$ \\ ${ }^{1}$ Department of Endocrinology, JinLing Hospital, Nanjing, Jiangsu, China \\ ${ }^{2}$ Department of Geriatrics, Geriatric Research Center, JinLing Hospital, \\ Nanjing, Jiangsu, China \\ Corresponding author: W.-H. Wan \\ E-mail: wanwhnj@sina.com
}

Genet. Mol. Res. 13 (1): 220-227 (2014)

Received June 5, 2013

Accepted October 15, 2013

Published January 14, 2014

DOI http://dx.doi.org/10.4238/2014.January.14.1

\begin{abstract}
Although ginkgo biloba extract (GBE) was shown to have antioxidant effects, little has been reported on the ability to GBE to help endothelial progenitor cells (EPCs) resist oxidative stress. The present study evaluated the influence of different concentrations of GBE on superoxide dismutase (SOD) and apoptosis of diabetic peripheral blood EPCs. Twenty-five diabetic patients without any vascular complications were included in the experimental group, while 15 healthy adults made up the control group. Peripheral blood mononuclear cells were isolated with density gradient centrifugation, and, after in vitro differentiation, were determined to be EPCs using FITC-UEA-I and Dil-Ac-LDL dual staining. After the colony and fusiform adherent cells were observed, on day 7 , various concentrations of ginkgo biloba extract $(0,10,25,50$ $\mathrm{mg} / \mathrm{L}$ ) were added to the culture medium for a $24-\mathrm{h}$ incubation. EPCSOD activity and apoptosis were subsequently detected. We found that within the experimental group, GBE significantly improved SOD
\end{abstract}


activity within EPCs and reduced the rate of apoptosis. These effects became more obvious with increasing GBE concentrations $(25 \mathrm{mg} / \mathrm{L}$, $\mathrm{P}<0.05 ; 50 \mathrm{mg} / \mathrm{L}, \mathrm{P}<0.01)$. GBE also improved SOD activity and reduced the rate of apoptosis within EPCs of the control group; however, the changes were not statistically significant. We conclude that GBE can improve SOD activity and reduce the rate of apoptosis of EPCs within the peripheral blood of diabetic patients, effects that are dose-dependent.

Key words: Ginkgo biloba extract; Endothelial progenitor cells; Superoxide dismutase; Apoptosis

\section{INTRODUCTION}

Endothelial progenitor cells (EPCs) are precursor cells that can differentiate into vascular endothelial cells under specific conditions to form new blood vessels, and, thus, are the key cells of vascular repair (Fadini and Avogaro, 2010). The overproduction of reactive oxygen species (ROS) and rise in the level of oxidative stress in the diabetic state damages EPCs function (Galasso et al., 2006). Nitric oxide (NO) is the master regulator of EPC mobilization, differentiation, and function, and ROS that produce excessive levels of the superoxide anion $\mathrm{O}_{2}^{-}$and peroxynitrite affect the bioavailability of NO to reduce its beneficial effects on EPCs (Thum et al., 2007). Since EPCs play an important role in the neovascularization and reendothelialization of ischemic damaged blood vessel tissues, their integrity and functional activities are critical in diabetic vascular disease. In the diabetic state, the overproduction of reactive oxygen causes an increased EPC apoptosis rate, thereby damaging the integrity of the cells. In this way, the increased rate of EPC apoptosis in diabetes is an important part of endothelial dysfunction and, consequently, the development of diabetic atherosclerosis (Zhang et al., 2010). Enhancing superoxide dismutase (SOD) activity would increase the ability of EPCs to resist oxidative stress, owing to the fact that the SOD enzyme neutralizes the superoxide anion $\mathrm{O}_{2}^{-}$(Galasso et al., 2006). Ginkgo biloba extract (GBE) is mainly composed of flavonoids and lactones, which have antioxidant, oxygen free radicals removal, and anti-aging functions. In the present study, GBE was added to EPCs in vitro to evaluate the effects of GBE on EPC apoptosis and SOD activity.

\section{MATERIAL AND METHODS}

\section{Subjects}

Peripheral blood $(20 \mathrm{~mL})$ from 15 healthy adults was collected for the control group, while peripheral blood $(20 \mathrm{~mL})$ from 25 diabetic patients was collected to represent patients. Inclusion criteria were as follows: non-smoking, healthy volunteers and diabetic patients $>$ 30 years old. Exclusion criteria were 1) smoking; 2) recent trauma and surgery; 3 ) long-term use of vitamin C, vitamin E, and other antioxidants, lipid-lowering drugs, non-steroidal antiinflammatory drugs, and hormone or immunosuppressant drugs, all of which would affect the state of oxidative stress; and 4) an association with the coronary artery disease, cerebrovascular diseases, diabetic vascular complications, diabetic nephropathy, retinopathy, or other microvascular complications, all of which would affect EPCs. 


\section{Reagents}

The human lymphocyte separation Ficoll-paque medium was purchased from Haoyang biotechnology company (Tianjin, China), while M199 medium and fetal bovine serum were purchased from Hyclone (Thermo Scientific Cell Culture and BioProcessing USA). Fibronectin was purchased from the R\&D Systems, Inc. (Minnesota USA), VEGF, bFGF, IGF-1, and EGF were purchased from Peprotech (PeproTech Inc. China), and FITC-UEAI, and Dil-Ac-LDL were purchased from Sigma(Sigma-Aldrich, St. Louis, MO, USA). 4\% paraformaldehyde and trypsin were purchased from Taize Ruida Technology Co. Ltd. (Beijing China), Laboratory supplies were purchased from Dingguo biotechnology company. (Nanjing China) GBE was purchased from Zelang Pharmaceutical Technology Co., Ltd. (Nanjing China). The SOD detection kit was purchased from Jiancheng BioEngineering Research Institute (Nanjing China). The AnnexinV-FITC/PI apoptosis detection kit was purchased from Beibo bio-Technology Co. Ltd. (Shanghai China).

\section{EPC separation}

$0.2 \mathrm{~mL}$ sodium heparin anticoagulant was added to $20 \mathrm{~mL}$ adult peripheral blood, and the mixture was serially diluted with Phosphate Buffer Solution (PBS). Human peripheral blood lymphocyte separation medium was then added at a 1:2 ratio (Liu et al., 2005). After centrifugation at $2500 \mathrm{rpm}$ was performed for $30 \mathrm{~min}$, the middle white layer containing the mononuclear cells was sucked out. Two milliliters of saline was added to generate the appropriate dilution, and a final centrifugation at $2500 \mathrm{rpm}$ was performed for $5 \mathrm{~min}$.

\section{Induced differentiation}

Fibronectin was dissolved and diluted for generation of a $1 \mu \mathrm{g} / \mathrm{mL}$ concentration. 24well plates were coated with $200 \mu \mathrm{L}$ of fibronectin in each well. Incubation was performed at $37^{\circ} \mathrm{C}$ overnight, and excess liquid was sucked out before use. Isolated mononuclear cells at $1-2 \times 10^{6} / \mathrm{mL}$ were vaccinated to the 24-well plates, with each specimen inoculating 12 holes. $20 \%$ fetal bovine serum, $10 \mathrm{ng} / \mathrm{mL}$ VEGF, $2 \mathrm{ng} / \mathrm{mL}$ bFGF, $2 \mathrm{ng} / \mathrm{mL}$ IGF, $10 \mathrm{ng} / \mathrm{mL}$ EGF (Liu et al., 2005), $0.5 \mu \mathrm{L}$ of penicillin and streptomycin each, and $0.5 \mathrm{~mL} \mathrm{M199}$ medium were also added to each well. The plates were placed in a $37^{\circ} \mathrm{C}$ culture incubator with $5 \% \mathrm{CO}_{2}$ for a day. PBS was then used to wash away nonadherent cells, and the medium was changed every 4 days. EPCs morphological changes are shown in Figure 1.

\section{EPC identification}

Using the methods described above, M199 medium containing serum and various cytokines was used in a 6-well plate to make mononuclear cells climb sheets for 7 days, and then sheets were removed and washed twice with pure M199 medium. Dil-Ac-LDL $(10 \mu \mathrm{g} / \mathrm{mL})$ was added in the dark, and adherent cells were incubated for $4 \mathrm{~h}$ at $37^{\circ} \mathrm{C}$. After another 3 washes with pure M199 medium, $2 \%$ paraformaldehyde was used to fix the cells for $10 \mathrm{~min}$. Then the cells were washed another 3 times with PBS. FITC-UEA-I $(10 \mu \mathrm{g} / \mathrm{mL})$ was then added to the samples in the dark, and adherent cells were incubated for $1 \mathrm{~h}$ at $37^{\circ} \mathrm{C}$, after which they were washed 3 times with PBS, and 
then observed inversely with a fluorescence microscope. The intake of Dil-Ac-LDL created red staining, while FITC-UEA-I labeling was seen as green staining, and, thus, double positive cells with a yellow stain were identified as EPCs (Churdchomjan et al., 2010) (Figure 2).
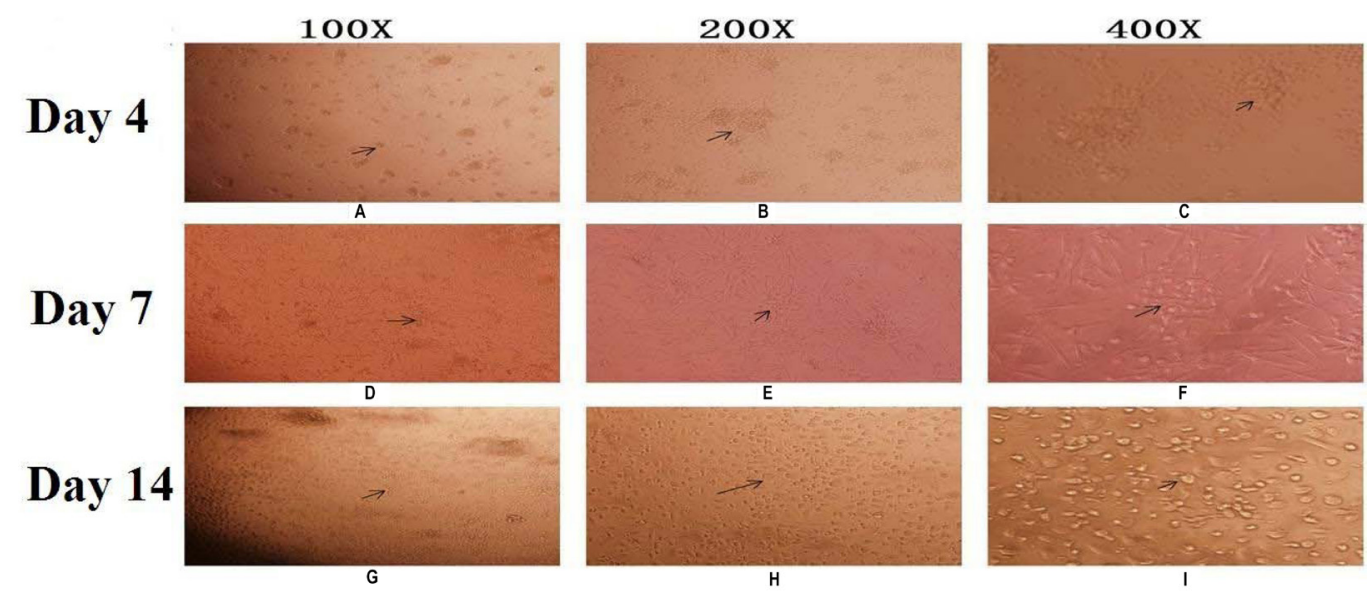

Figure 1. Morphological observation of EPCs. A. B. C. On the fourth day of the EPC culture, there appeared a cluster of the round cells, the tend of a cell colony was formed. D. E. F. On the seventh day of the EPC culture, there appeared a circular cell cluster in the center, the outside adherent cells in the spindle shuttle shape were called a colony, which was also known as the early EPCs. G. H. I. On the fourteenth day of the EPC culture, part of the adhenrent cells showed the cobblestone morphology change; they were similar to the mature endothelial cells and had become the late EPCs. (100x, 200x, 400x, respectively).
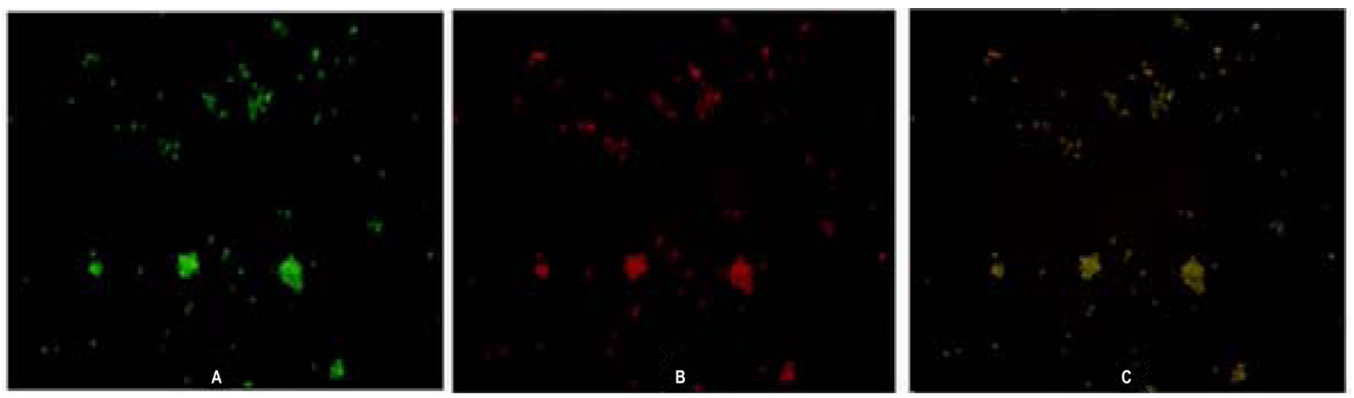

Figure 2. Picture of characterization of the EPCs. A. EPCs stained the FITC-UEA-I into green. B. Dil-Ac-LDL phagocytosis showed the red color. C. Double positive cells, which presented the yellow staining, were identified as the EPCs.

\section{Detection of SOD activity}

The cell culture medium was changed on the 7 th day, at which point various concentrations of GBE medium, specifically $0,10,25$, and $50 \mathrm{mg} / \mathrm{L}$ (Banerjee et al., 2006), were added. Three wells per concentration were set up, and after $24 \mathrm{~h}$ of the drug intervention, the cell supernatant was extracted and examined SOD activity according to the instructions of the SOD detection kit. 


\section{EPC apoptosis detection}

The cell culture medium was changed on the 7th day, at which point various concentrations of GBE medium, specifically $0,10,25$, and $50 \mathrm{mg} / \mathrm{L}$ (Banerjee et al., 2006) were added. Three wells per concentration were set up, and after $24 \mathrm{~h}$ of the drug intervention, the cell supernatant was extracted. $40 \mu \mathrm{L}$ of trypsin was then added to each well for digestion adherent cell for 3 to $5 \mathrm{~min}$, and $160 \mu \mathrm{L}$ of serum was added for pipetting the adherent cell. The resultant collected EPCs were washed 2 times with PBS and resuspended in a binding solution, following which $5 \mu \mathrm{L}$ AnnexinV-FITC was successively added for $15 \mathrm{~min}$ of the $4^{\circ} \mathrm{C}$ incubation, and then cells were added to $10 \mu \mathrm{L}$ PI for $5 \mathrm{~min}$ at $4^{\circ} \mathrm{C}$, until flow detection.

\section{Statistical analysis}

The quantitative data are reported as mean \pm standard deviation (means $\pm \mathrm{SD}$ ). Oneway ANOVA (analysis of variance) was used to compare means among different groups, and the LSD (least significant difference) $t$ test was used for comparisons between two groups. Results with $\mathrm{P}<0.05$ values were considered statistically significant. SPSS 17.0 software was used for statistical analysis.

\section{RESULTS}

\section{Spectrophotometer detection of SOD activity in EPCs after 24-h incubation with different concentrations of GBE}

In the experimental group, $10 \mathrm{mg} / \mathrm{L}$ of GBE improved EPC SOD activity but the effect was not significant $(\mathrm{P}>0.05)$, while GBE at $25 \mathrm{mg} / \mathrm{L}$ and $50 \mathrm{mg} / \mathrm{L}$ significantly increased EPC SOD activity $(\mathrm{P}<0.05)$. The GBE effects of GBE were more obvious with increasing concentrations. In the control group, although each GBE concentration tested improved EPC SOD activity, the changes were not statistically significant $(\mathrm{P}>0.05)$. Results were shown in Table 1.

\begin{tabular}{|c|c|c|c|c|}
\hline GBE concentration & $\begin{array}{l}\text { No. of subjects in } \\
\text { the control group }\end{array}$ & $\begin{array}{l}\text { SOD activity in the } \\
\text { control group }\end{array}$ & $\begin{array}{l}\text { No. of cases in the } \\
\text { experimental group }\end{array}$ & $\begin{array}{l}\text { SOD activity in } \\
\text { the experimental group }\end{array}$ \\
\hline $0 \mathrm{mg} / \mathrm{L}$ & 15 & $24.49 \pm 0.90$ & 25 & $26.91 \pm 0.54$ \\
\hline $10 \mathrm{mg} / \mathrm{L}$ & 15 & $25.56 \pm 0.95$ & 25 & $28.05 \pm 0.50$ \\
\hline $25 \mathrm{mg} / \mathrm{L}$ & 15 & $26.25 \pm 1.04$ & 25 & $29.92 \pm 0.61$ \\
\hline $50 \mathrm{mg} / \mathrm{L}$ & 15 & $26.77 \pm 0.99$ & 25 & $34.15 \pm 0.51$ \\
\hline
\end{tabular}

\section{Flow cytometry detection of EPC apoptosis after 24-h incubation with different concentrations of GBE}

In the experimental group, the EPC apoptosis rate increased proportional to GBE concentration decreases $(\mathrm{P}<0.05)$, with the most significant effects on the reduction of the $\mathrm{EPC}$ apoptosis rate being observed with $50 \mathrm{mg} / \mathrm{L}$ of GBE $(\mathrm{P}<0.01)$. In the control group, the 
various concentrations of the GBE reduced the EPC apoptosis rate, but the findings were not statistically significant $(\mathrm{P}>0.05)$. Results were shown in Table 2 and Figure 3.

Table 2. Apoptosis rate of EPCs with ginkgo biloba extract (GBE) in a series of concentrations $(0,10,25,50$
$\mathrm{mg} / \mathrm{L})$ for $24 \mathrm{~h}$ were measured by fluorescence-activated cell sorting (FACS).
\begin{tabular}{|lcccc}
\hline GBE concentration & $\begin{array}{l}\text { No. of subjects in } \\
\text { the control group }\end{array}$ & $\begin{array}{c}\text { Apoptosis rate in the } \\
\text { control group }\end{array}$ & $\begin{array}{c}\text { No. of cases in the } \\
\text { experimental group }\end{array}$ & $\begin{array}{r}\text { Apoptosis rate in the } \\
\text { experimental group }\end{array}$ \\
\hline $0 \mathrm{mg} / \mathrm{L}$ & 15 & $4.02 \% \pm 0.14$ & 25 & $19.95 \% \pm 0.42$ \\
$10 \mathrm{mg} / \mathrm{L}$ & 15 & $3.77 \% \pm 0.10$ & 25 & $17.66 \% \pm 0.60$ \\
$25 \mathrm{mg} / \mathrm{L}$ & 15 & $3.64 \% \pm 0.17$ & 25 & $13.63 \% \pm 0.43$ \\
$50 \mathrm{mg} / \mathrm{L}$ & 15 & $3.40 \% \pm 0.15$ & 25 & $9.65 \% \pm 0.35$ \\
\hline
\end{tabular}
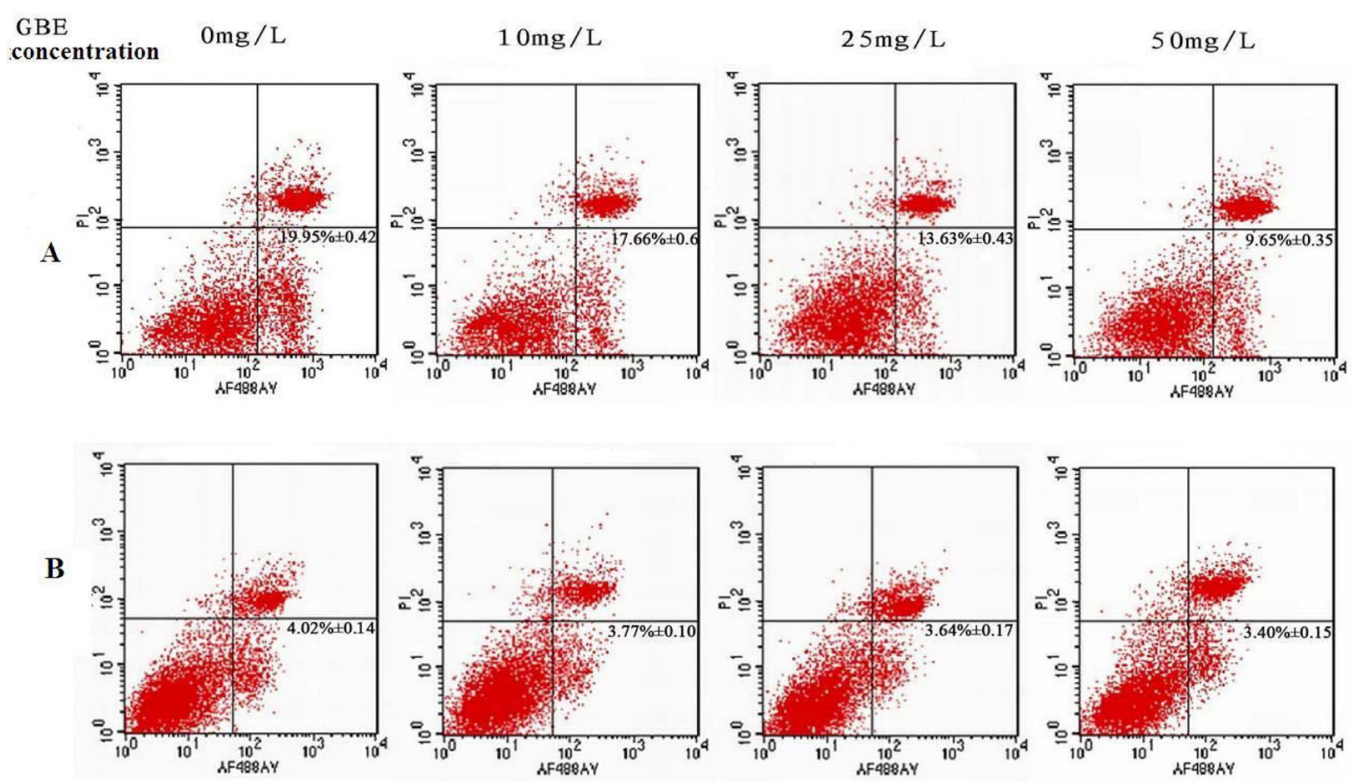

Figure 3. Apoptosis of EPCs with AnnexinV-FITC/PI dyeing analyzed by fluorescence-activated cell sorting (FACS): A. experiment group; B. control group.

\section{DISCUSSION}

EPCs are precursor cells that can differentiate into endothelial cells and have functions in migration, proliferation, and adhesion. They are not only involved in the formation of the embryonic blood vessel, but are also involved in adult neovascularization (Zhou et al., 2010). The number and function of EPCs is positively related to endothelial function and vascular regeneration, but negatively correlated with cardiovascular risk factors. Indeed, a reduction in the number of EPCs is a warning signal for atherosclerotic morbidity and mortality (Foresta et al., 2010). In terms of the developmental process of diabetic, atherosclerotic disease, the lack of EPCs for artery repair is one of the main contributors, in addition to age. Geneticsbased molecular evidence revealed that the early form of atherosclerotic lesion was due to insufficient artery repair rather than arterial injury (Goldschmidt-Clermont et al., 2010). Arte- 
rial injury may overwhelm the ability of EPCs to maintain arterial homeostasis, particularly when EPCs capable of arterial repair become exhausted. Furthermore, EPC apoptosis caused an increase in endothelial permeability, resulting in the adherence of blood cells to the vessel wall and the rupturing of plaque, and then the subsequent formation of thrombus (Dernbach et al., 2004). These processes directly led to the development of diabetes-related complications.

The oxidative stress response is one of the most important factors in the pathogenesis of diabetes and its complications. Bone marrow-derived EPCs play the key role in angiogenesis and the homing of peripheral blood in wound healing. Endothelial cell nitrogen oxide synthase (eNOS) expression and phosphorylation are essential for the survival, migration, and angiogenesis of EPCs. Under the normal circumstances, eNOS can synthesize NO with arginine as its substrate and tetrahydrobiopterin (BH4) as assisting material. In the state of oxidative stress, however, BH4 is oxidized to inactivate eNOS uncoupling, so that EPC mobilization from the bone marrow to peripheral blood is decreased. Banerjee et al. (2006) found that oxidative stress was an important apoptosis inducing factor. A high glucose level either increased cell metabolism or caused metabolic disorders, which consequently may increase intracellular ROS levels and cause the glutathione redox circulation disorder. The ability to remove free oxygen radicals within cells decreased and apoptosis was induced. GBE reduces the apoptosis rate of retinal vascular endothelial cells, which was closely related to remove free oxygen radicals, an anti-oxidation function, and affecting glucose metabolism. Consistent with the previous results discussed above, our study found that, owing to the antioxidant characteristics of GBE, different concentrations of GBE affected EPCs in vitro, to increase EPC SOD activity and decrease the apoptosis rate in a dose-dependent manner. It can be concluded, therefore, that ROS play an important role in diabetes. Increases in the EPC apoptosis rate and changes in SOD activity have been associated with a continuous increase in inflammatory factors and oxidative stress levels in diabetes (George et al., 2004). Another study (Hamed et al., 2009) found that although the treatment of the diabetes with insulin can increase NO production by EPCs, it cannot change $\mathrm{O}_{2}^{-}$production and colony forming ability. The combination of SOD and insulin therapy, however, would significantly improve the situation. Research by Hamed et al. (2009) showed that SOD has an essential role in EPCs, and stressed the importance of antioxidant treatment in diabetes.

Bone marrow derived EPCs are entirely responsible for the management and protection of the endothelial cells, with their effects being the same in angiogenesis. The number and function of EPCs in the peripheral circulation is a powerful marker of vascular injury for most diseases that is independent from other traditional and non-traditional pathogenic factors, such as hypertension, hypercholesterolemia, and c-reactive protein levels. Studies have shown that exogenous EPC injection into mice has vascular repair capacity by means of reducing pathogenic factors and improving endothelial repair function in ischemic tissue. Based on this cellular therapy, autologous EPCs provide new treatment options for revascularization and vascular repair in diabetes patients. EPCs used for cell transplantation, however, retained dysfunctional characteristics in the body (Jarajapu and Grant, 2010), which affected the feasibility of this therapeutic program. Moreover, vascular pathogenic factors in the diabetic patient's bodies were variable. In clinical circumstances, EPC number and function changes alone cannot then adequately affect the progression of blood vessel disease. These changes were also observed in the outer membranes of cells such as smooth muscle cells and macrophages (Sen et al., 2011). In the treatment of diabetic vascular disease with the EPCs, therefore, a joint strategy may be 
needed to adjust the function of surrounding cells to ultimately affect EPCs and achieve the most optimal treatment regimens. Since the effects among different cells are complicated by many factors, which has not been fully elucidated and requires further research.

\section{REFERENCES}

Banerjee S, Brilakis E, Zhang S, Roesle M, et al. (2006). Endothelial progenitor cell mobilization after percutaneous coronary intervention. Atherosclerosis 189: 70-75.

Churdchomjan W, Kheolamai P, Manochantr S, Tapanadechopone P, et al. (2010). Comparison of endothelial progenitor cell function in type 2 diabetes with good and poor glycemic control. BMC Endocr. Disord. 10: 5.

Dernbach E, Urbich C, Brandes RP, Hofmann WK, et al. (2004). Antioxidative stress-associated genes in circulating progenitor cells: evidence for enhanced resistance against oxidative stress. Blood 104: 3591-3597.

Fadini GP and Avogaro A (2010). Potential manipulation of endothelial progenitor cells in diabetes and its complications. Diabetes Obes. Metab. 12: 570-583.

Foresta C, De Toni L, Ferlin A and Di MA (2010). Clinical implication of endothelial progenitor cells. Expert Rev. Mol. Diagn. 10: 89-105.

Galasso G, Schiekofer S, Sato K, Shibata R, et al. (2006). Impaired angiogenesis in glutathione peroxidase-1-deficient mice is associated with endothelial progenitor cell dysfunction. Circ. Res. 98: 254-261.

George J, Goldstein E, Abashidze S, Deutsch V, et al. (2004). Circulating endothelial progenitor cells in patients with unstable angina: association with systemic inflammation. Eur. Heart J. 25: 1003-1008.

Goldschmidt-Clermont PJ, Seo DM, Wang L, Beecham GW, et al. (2010). Inflammation, stem cells and atherosclerosis genetics. Curr. Opin. Mol. Ther. 12: 712-723.

Hamed S, Brenner B, Aharon A, Daoud D, et al. (2009). Nitric oxide and superoxide dismutase modulate endothelial progenitor cell function in type 2 diabetes mellitus. Cardiovasc. Diabetol. 8: 56.

Jarajapu YP and Grant MB (2010). The promise of cell-based therapies for diabetic complications: challenges and solutions. Circ. Res. 106: 854-869.

Liu ZH, Lei MX, Wang AM and et al. (2005). Adult endothelial progenitor cell separation and induction of differentiation. Acta Central-South Univ. 30: 566-569.

Sen S, McDonald SP, Coates PT and Bonder CS (2011). Endothelial progenitor cells: novel biomarker and promising cell therapy for cardiovascular disease. Clin. Sci. 120: 263-283.

Thum T, Fraccarollo D, Thum S, Schultheiss M, et al. (2007). Differential effects of organic nitrates on endothelial progenitor cells are determined by oxidative stress. Arterioscler. Thromb. Vasc. Biol. 27: 748-754.

Zhang LJ, Liu WX, Chen YD, Song XT, et al. (2010). Proliferation, migration and apoptosis activities of endothelial progenitor cells in acute coronary syndrome. Chin. Med. J. 123: 2655-2661.

Zhou X, Xin XY and Huang YF (2010). Detection of circulating endothelial cells and its application in clinical oncology progress. Med. Postgraduates 23: 543-546. 